\title{
Efficacy, Tolerability, Compliance, and cost of ferrous sulfate versus iron polymaltose complex capsules: a randomized trial in pregnant women with iron deficiency anemia
}

Mohamed Anwar Elnory', Ashraf Nassif Mahmoud Elmantwe ${ }^{2}$ 'Assistant Professor of Obstetrics and Gynecology, Benha Faculty Of Medicine, Benha University, Egypt./elnorymh1962@gmail.com

${ }^{2}$ Assistant Professor of Obstetrics and Gynecology, Benha Faculty Of Medicine, Benha University, Egypt./Ashrafnassif2002@yahoo. com

/Ashrafnassifelmantwe@fmed. bu.edu.eg/+20 01001801244
Mohamed Anwar Elnory Assistant Professor of Obstetrics and Gynecology, Benha Faculty Of Medicine, Benha University, Egypt./elnorymh1962@gmail.com

\begin{abstract}
$\underline{\text { Abstract }}$
Aim: The main objective of this trial was to compare the therapeutic efficacy, gastrointestinal and systemic tolerability as well as compliance on oral medicinal iron consumption and total related drugs costs between sustained released ferrous sulphate (SRFS) oral capsules and soft gelatinous capsules of non-ionic ferric $\left(\mathrm{Fe}^{+3}\right)$ polymaltose complex (IPC) in treating gestational iron deficiency anemia (GIDA) in second $\left(2^{\text {nd }}\right)$ and early third $\left(3^{\text {rd }}\right)$ trimester.
\end{abstract}

Patients and Methods: This prospective, open-label, randomized, parallel group, concealed allocation, controlled, multicenter superiority trial was conducted at Benha University Hospital (BUH) and two private clinics in El-Qalubia, Egypt, from October 2016 to December 2017. We screened 500 pregnant women, 310 women were eligible and consented to participate in GIDA trial. All women included were had typical mild or moderate iron deficiency anemia (IDA) as their hemoglobin (HB), and serum ferritin (SF) was $\leq 10.5$ or 11 to $\geq 8 \mathrm{gm} / \mathrm{dl}$ and $\leq 15 \mathrm{ng} / \mathrm{ml}$ respectively. 155 women were allocated to either consume $100 \mathrm{mg}$ elemental iron (EI) of dried SRFS (60 capsules of ferroful ${ }^{\circledR} /$ four weeks) in the SRFS arm or $100 \mathrm{mg}$ EI of IPC (28Haemojet ${ }^{\circledR}$ capsules $/ 4$ weeks) in IPC arm. Main outcomes were the change $(\Delta)$ in HB and SF at 4 weeks $\left(T_{1}\right), 8$ weeks $\left(\mathrm{T}_{2}\right), 12$ weeks $\left(\mathrm{T}_{3}\right)$ from baseline levels $\left(\mathrm{T}_{0}\right)$ as well as incidence of gastrointestinal and systemic adverse side events (ASE) of consumed oral iron capsules and women compliance on drug intakes in addition to direct and indirect drug costs.

Results: 298 women started oral iron intake , 150 in SRFS arm and 148 in IPC arm, while at the end of study period (12 weeks), 20 $(12.9 \%)$ women in SRFS versus $4(2.6 \%)$ in IPC had severe ASE and stopped consumption of oral iron $(\Delta \mathrm{pp} 10.3 \%$ at $95 \%$ C.I of 4.44 , $16.68, \mathrm{P}=0.0004)$. At any follow up periods $\mathrm{T} 1, \mathrm{~T} 2$, T3 the changes in HB were significantly higher in IPC group $(\mathrm{P}=0.0001, \mathrm{P}=$ $0.0064, \mathrm{P}=0.012)$ and changes in SF between T3 and T0 was (58.11 \pm 32.34 in SRFS vs $69.63 \pm 13.61$ with $\Delta 95 \%$ CI of $-11.52(-5.97$, $-17.06, \mathrm{P}=0.0001)$. Also percentage of women who consumed $\geq$ $75 \%$ of oral iron capsules / 4 weeks were significantly higher in IPC arm than SRFS arm $\mathrm{P}=0.006, \mathrm{P}=0.040, \mathrm{P}=0.007$. Moreover, the total costs of direct and indirect used drugs were significantly less in IPC arm than SRFS group at T1, T2, T3(P $<0.0001, \mathrm{P}<0.0001, \mathrm{P}<$ $0.0001)$. No severe sequels were noted in pregnancy outcomes could be attributed to used medicinal oral iron. 
Conclusion: Oral non - ionic ferric $\left(\mathrm{Fe}^{+3}\right)$ iron polymaltose complex was more effective, more tolerable as well as women were more complaint on its consumption and its total costs were lower than sustained released ferrous sulfate dried capsules in treating mild and moderate gestational iron deficiency in second and early third trimesters.

Key Words: Iron polymaltose complex, Sustained released ferrous sulfate, Gestational iron deficiency anemia, Iron deficiency anemia, Hemoglobin, Serum Ferritin.

\section{Introduction}

Gestational iron deficiency anemia (GIDA is a prevalent problem affecting up to $25 \%$ in developed countries and up to $52 \%$ in developing countries like Egypt $^{(1)}$. GIDA has a superadded obstetrical risks over that occurred with iron deficiency anemia (IDA) as dyspnea, fatigue, headaches, palpitations, and irritability. GIDA increases maternal morbidities as infection, hemorrhage, and mortality as well as results in poor neonatal outcomes, including preterm birth, fetal growth retardation, low birth weight and perinatal death ${ }^{(2,3,4)}$.

Identifying women with iron deficiency (ID) and iron deficiency anemia (IDA) is crucial step in management so, WHO, US center for disease control and prevention (CDC) and UK guidelines recommended screening for IDA and ID during pregnancy as well as oral iron supplementation specially ferrous salts e.g. ferrous sulphate (FS) and may be others as iron polymaltose complex (IPC) of 60 $\mathrm{mg}$ elemental iron (EI) in cases of no IDA and up to $120 \mathrm{mg}$ EI in cases of $\operatorname{IDA}^{(5,6,7,8)}$. CDC defined GIDA as hemoglobin $(\mathrm{HB}) \leq 11 \mathrm{gm} / \mathrm{dl}$ in first $\left(1^{\text {st }}\right)$ and the third $\left(3^{\text {rd }}\right)$ pregnancy trimesters and $\leq 10.5$ $\mathrm{gm} / \mathrm{dl}$ for the $2^{\text {nd }}$ trimester $^{(6)}$, while WHO takes HB $\leq 11 \mathrm{gm} / \mathrm{dl}$ as cut of for GIDA in general $(1,5)$, moreover UK guidelines considered serum ferritin $(\mathrm{SF}) \leq 30 \mathrm{ng} / \mathrm{ml}$, as marker for ID and $\leq 15 \mathrm{ng} / \mathrm{ml}$ as cut of for GIDA diagnosis ${ }^{(7)}$. Management of ID \& IDA during pregnancy still poses challenges to pregnant women, obstetricians, families as well as communities, as they need to change food consumption, to fortify supplied food with iron as well as to consume medicinal iron supplementation as recommended by many national and international authorities $^{(5,6,7,8)}$.
Almost always, cases of mild and moderate IDA during pregnancy respond in a proper way to oral iron supplementation ${ }^{(9,10)}$ and rise in $\mathrm{Hb}$ concentration of $2 \mathrm{gm} / \mathrm{dl}$ over $3-4$ weeks considered a satisfactory response to oral medicinal iron ${ }^{(7)}$. Pregnant women compliance on oral medicinal iron is highly needed to achieve such response. In general this compliance on oral iron is hindered during pregnancy and this lack of compliance is more with oral ferrous salts secondary to its gastrointestinal (GIT) adverse side events (ASE) as nausea, vomiting, epigastric pain, diarrhea, dark stool, abdominal colicky pain and constipation in up to $30 \%$ of pregnant women $(6,9,10)$. Such iron related ASE are minimal with iron polymaltose complex (IPC) $)^{(9,10,4,12,13,14)}$.

A lot of clinical researches compared between ferrous salts and IPC in adults, as well as in Children's ${ }^{(11,12,13,14)}$. However regards comparing ferrous sulfate especially sustained released (SR) formulations to IPC capsules in high doses as recommended with WHO for treating IDA as regards therapeutic clinical efficacy, gastrointestinal tolerability as well as compliance with the medication and regards its costs in pregnant women, the trials were few ${ }^{(15,16,17,18)}$. Therefore, we conduct this trial to compare between dried sustained release ferrous sulphate(SRFS) hard capsules versus IPC oral formulations at dose of $100 \mathrm{mg}$ EI / day as regards therapeutic clinical efficacy, tolerability and compliance as well as the cost in pregnant women with mild/moderate IDA in $2^{\text {nd }}$, and early $3^{\text {rd }}$ trimesters.

\section{Patients and Methods}

We performed this prospective, concealed allocation, randomized, parallel group, open-label (pregnant women, observers, caregivers and investigators were known the used medication nature, as we could not get identical commercially medicinal iron containing SRFS and IPC), superiority trial at Benha University Hospital (BUH) obstetrics and gynecology department out patients clinic, (MAE) clinic at Benha City and (ANME )clinic at Abozobal City, all centers were in Al-Qalubia, Egypt, from October 2016 to September 2017. We get approval from Benha Faculty of Medicine ethical committee for this trial's protocol; also all partici- 
pants in this trial signed written informed consents after careful counseling regarding giving their full contacts, blood sampling and reminding them with next follow up visits before enrolling in this trial. All pregnant women with symptoms and signs suggestive of IDA in $2^{\text {nd }}$ and early 3 rd trimesters were assessed $\left(\mathrm{T}_{0}\right)$ with complete blood picture (CBC) and serum ferritin (SF) and whom found to have IDA $\left(\mathrm{HB}<10.5 \mathrm{gm} / \mathrm{dl}\right.$ in $2^{\text {nd }} \mathrm{TM}$ or $\mathrm{HB}<11 \mathrm{gm} / \mathrm{dl}$ in early $3^{\text {rd }} \mathrm{TM}$ up to 32 weeks and $\mathrm{SF}<15 \mathrm{ng} / \mathrm{ml}$ ) without any exclusion were asked to participate. Eligible participants were pregnant women between 18 and 40 years old, $14-32$ weeks of gestation with a singleton fetus without any detectable fetal abnormalities. Exclusion criteria were clinical or/ and laboratory evidence of renal, hepatic, cardiovascular, hematological, endocrinal abnormalities; history of hiatalhernia, esophagitis, acid - peptic disorders or of any other medical disorder as well as use of hematinic medicinal agents within 4 weeks prior to inclusion or with chronic blood loss or hypersensitivity to oral iron formulations; family history of hemolytic anemia, thalassemia sickle cell anemia or malabsorption syndrome. Women with pregnancy induced medical disorder before the study were also excluded, while whom developing mild pregnancy induced medical disorder after inclusion were continued, only who developed severe pregnancy induced medical condition were excused from completing the oral iron preparation but included in the trial final analysis. Participants were sequentially recruited and allocated to the SRFS group or IPC group randomly at 1: 1 ratio. The trial statistician using computer number generator created a randomized treatment allocation schedule of 31 blocks each of (10) participants, and six blocks were stored at BUH, 16 Block stored at MAE clinic and nine blocks at ANME clinic. Women in SRFS group were received 2 capsules either at $\geq 1 / 2$ before or $\geq 1$ hour After the same choosing meal everyday and extra capsule to be taken every week, so a dose of $100 \mathrm{mg}$ EI were taken daily with $1 \mathrm{mg}$ folic acid as well as capsule additives for 12 weeks (FERROFUL $\AA$, spansule capsule contain 150 dried ferrous sulphate giving $47 \mathrm{mg}$ EI with $0.5 \mathrm{mg}$ folic acid, EIPICO, $10^{\text {th }}$ of RAMDAN city, Egypt). Also, women in the SRFS group instructed to avoid intake of foods or mediations that may interfere with FS absorption. Women in IPS group received daily $100 \mathrm{mg}$
EI for 12 weeks (Haemojet ${ }^{\circledR}$, soft Gelatin capsule each capsule contain $322.5 \mathrm{mg}$ ferric hydroxide polymaltose complex plus inactive ingredients, EUROPEAN EGYPTIAN PHARMACEUTICAL INDUSTRIES, ALEXADRIA - EGYPT). Women in the IPS group instructed to receive one capsule daily at a fixed time as she wants. In IPS groups $1 \mathrm{mg}$ folic acid was added daily as divided tablet of $5 \mathrm{mg}$ of NILE pharmaceutical company, so in both groups, the same hematinic agents were supplied and so the therapeutic difference could be attributed only to the type of supplied medicinal iron namely SRFS or IPC.

Women in both groups were followed up at four weeks $\left(\mathrm{T}_{1}\right)$, at eight weeks $\left(\mathrm{T}_{2}\right)$ and 12 weeks $\left(\mathrm{T}_{3}\right)$ after enrollment at $\left(\mathrm{T}_{0}\right)$. At $\left(\mathrm{T}_{0}\right)$ women were evaluated for clinical symptoms and signs of IDA and venous sample were taken for assessment of CBC and $\mathrm{SF}$, also at end visit $\left(\mathrm{T}_{3}\right)$ venous sample for assessing $\mathrm{CBC}$ and $\mathrm{SF}$ but at $\mathrm{T}_{1}, \mathrm{~T}_{2}$ we evaluated for CBC only. CBC \& SF evaluations were performed in governmental authorized laboratories on calibrated Machines. CBC was done on automated homocytometer (Mindray BC - 6800, China) while serum ferritin was assessed by human ferritin enzyme immunoassay test kit (Bioplus, Inc; South san Francisco, USA). Women in each group at follow up visits $T_{1}, T_{2}, T_{3}$ were evaluated regards medicinal iron tolerability by assessing their kept dairy of gastrointestinal symptoms that we provided it to them. Women were asked to recorded and quantify symptoms severity related to intake of oral iron as $0=$ absent, $1=$ mild, $2=$ moderate, $3=$ severe as regards nausea, vomiting, colicky abdominal colicky pain, diarrhea, constipation, dark stool, epigastric pain as well as recording any symptoms that may be related to medicinal iron intake. Women in both groups were evaluated at each follow up visits $\mathrm{T}_{1}, \mathrm{~T}_{2}, \mathrm{~T}_{3}$ regards compliance with oral medicinal iron intake verbally as well as objectively by counting empty capsules container strips. After completing the 12 weeks of the trial contact with enrolled women was kept, so pregnancy outcomes could be evaluated even that women were served away from BUH or investigators clinics.

The main outcomes measures were the therapeutic efficacy of medicinal oral iron on HB after 4,8, 12 weeks and on SF after 12 weeks as well as participants tolerability to oral medicinal iron via eval- 
uating the occurrence of iron related ASE and its severity and participants compliance on allocated oral iron and total cost of related drugs. Women classified according to compliance into 4 group (a) $=$ best complaint women who consumed $\geq 75 \%$ of calculated capsules, $\mathrm{b}=$ good complaint women, who consumed $\geq 50 \%$ and $<75 \%$ of calculated capsules $\mathrm{C}=$ fair complaint women who consumed $\geq 25 \%$ and $<50 \%$ of calculated capsules, $\mathrm{d}=$ poor complaint women who consumed $<25 \%$ of calculated capsules. Women were instructed to consume 28 capsules of Haemojet with seven tablets of folic in IPC group every four weeks while women in SRFS group instructed to use 60 capsules of fearful in the four week period.

We calculated different sample sizes to assess women with GIDA for SRFS or IPC usage compliance, therapeutic efficacy as well as gastrointestinal tolerability by an online website : clinicalc. Com/stats/sample size. aspx" and we found that the maximally calculated sample size was for detecting changes in HB difference with oral iron. A sample of 155 women in each group was considered sufficient to detect difference in $\triangle \mathrm{HB}$ at 8 weeks (IPC, $2.72 \pm 0.55$ versus FS $2.90 \pm 0.46$ ) (15) at $5 \%$ double sided significance (type I or $\alpha$ error $=0.05$ ) and power of $80 \%$ (type 2 or B error $=0.2$ ) using independent student $\mathrm{t}$ test by website as well as to compensate for up to $25 \%$ lost to follow up.

Statistical analysis was according to intention to treat analysis(ITT), where all included women in the trial were included in the final analysis as well as last observation carried forward (LOCF) for missing value and performed by SPSS package (SPSS, Chicago, IL, USA) version 18.5. Continuous variables as baseline demographic, clinical end laboratory criteria, changes in $\mathrm{HB}, \mathrm{SF}$ over visits follow up were presented in terms of mean \pm standard deviations (ranges) and tested for significance difference between FS and IPS groups with independent student $t$ test, while categorical variables such as incidence of gastrointestinal side events were presented as number and percentages and evaluated for significant differences between the two groups by fisher's exact test. We used the $p$ value as well as point estimates differences with $95 \%$ confidence interval to determined significance differences, and we considered $<0.05$ as statistically significant.

\section{$\underline{\text { Results }}$}

In total, 500 pregnant women in the second and early third trimesters were screened, 310 pregnant women were found to have GIDA and fulfill inclusion and exclusion criteria as well as consented to participate in GIDA trial. After allocation, five women in the SRFS arm and seven women in IPC arm withdrawn their consents without giving any reasons. While 150 women and 148 women started SRFS (Ferroful $\AA$ cap) and IPC (Haemojet ${ }^{\circledR}$ cap), respectively. Women included in this trial followed up every four weeks at first follow up $\left(\mathrm{T}_{1}\right) 4$ women and five women lost to follow up while eight women and two women asking for discontinuing using the medicinal iron in SRFS and IPC group, respectively. At the secand follow-up $\left(\mathrm{T}_{2}\right), 3$ and four women lost to follow up while 6 and one discontinued drug intake in SRFS and IPC groups. At closing the trial $\left(\mathrm{T}_{3}\right)$, an additional 4 and five women lost to follow up while 6 and one discontinued drug intake (Figure I).

Participants of GIDA trial were similar in both arms regards baseline demographic, clinical as well as laboratory characteristics, as presented in table (1).

Table (2) presents the therapeutic hematological efficacy differences between pregnant women with GIDA who received SRFS and IPC at dose of $100 \mathrm{mg}$ elemental iron daily and shows that hemoglobin levels at $\mathrm{T}_{1}, \mathrm{~T}_{2}, \mathrm{~T}_{3}$ were significantly higher in women receiving IPC $(\mathrm{P}=0.0002, \mathrm{P}=0.0001$, $\mathrm{P}=0.0025)$ respectively. Also table (2) shows that changes in HB from baseline to at any follow up period $\Delta_{1}\left(\mathrm{~T}_{1}-\mathrm{T}_{0}\right), \Delta_{2}\left(\mathrm{~T}_{2}-\mathrm{T}_{0}\right), \Delta_{3}\left(\mathrm{~T}_{3}-\mathrm{T}_{0}\right)$ were significantly high in women consuming IPC $(\mathrm{P}=$ $0.0001, \mathrm{P}=0.0064, \mathrm{P}=0.012$ ) respectively as well as the increase in serum ferritin as a representative for iron storage and changes in serum ferritin from baseline both were significantly higher in women allocated to IPC arm $(\mathrm{P}=0.001, \mathrm{P}=0.0001)$.

Table (3) shows that the adverse side events (ASE) were statistically significantly higher in women allocated to SRFS arm, where women in this groups frequently complained of nausea, vomiting, constipation, diarrhea, metallic taste, headache, epigastric discomfort, colicky abdominal pain, parities, and dyspnea. Also this table showed that women in SRFS arm expressed more severe ASE 
versus women in IPC [20/155 (12.9\%) vs 4/144 $(2.6 \%)$, proportion percentage difference $(\Delta \mathrm{PP})=$ $10.3 \%$ at $95 \% \mathrm{CI}$ of $(4.44 \%, 16.68 \%)]$ and relative risk $(\mathrm{RR})=5$ with $95 \%$ of 1.74 to 14.29 as well as NNT $($ Harm $)=10$ at $95 \%$ of 22.30 (Harm) to 6.18 (Harm), so we could save one pregnant women from complaining of severe ASE that induced by oral iron for every ten supplemented pregnant women with IPC formulations instead of SRFS formulations. Moreover table (3) shows that women without complaining of ASE were more in IPC arm than SRFS arm (65/155 (41.0\%)vs $32(20.6 \%)$ with $\triangle \mathrm{PP}=21.3 \%$ at $95 \% \mathrm{CI}$ of 11.02 to $30.97, \mathrm{P}$ $=0.0001$ ), odds ratio $=2.77 \%$ at $95 \% \mathrm{CI}$ of 1.67 to 4.59, $\mathrm{p}=0.0001$.

Table (4) presents the differences between GIDA trial arms regards patient's compliance with allocated medicinal iron as well as direct costs of SRFS and IPC capsules and indirect costs of treating iron related ASE. As shown in table (4) compliance with IPC (was higher at $\mathrm{T}_{1}, \mathrm{~T}_{2}, \mathrm{~T}_{3}$ follow up period as percentage of women consumed, more than $75 \%$ of calculated capsules were significantly more at $\mathrm{T}_{1}, \mathrm{~T}_{2}, \mathrm{~T}_{3}, \mathrm{P}=0.006, \mathrm{P}=0.04 \mathrm{vs}$, $\mathrm{P}=0.007$ respectively while percentage of women described as poor compliance as they consumed $<25 \%$ of calculated capsules were more in SRFS arm compared to IPC arm at T1, T2, T3 follow up periods $\mathrm{P}=0.001, \mathrm{P}=0.018, \mathrm{P}=0.02$. Table(4) also shows that total number of women stopped treatment with medicinal iron were more in SRFS group than IPC group (20/155 (12.9\%) vs 4 (2.5\%) with $\triangle \mathrm{PP} 10.4 \%$ at $95 \% \mathrm{CI}$ of 1.06 to $19.34, \mathrm{P}=$ $0.0006, \mathrm{RR}=5$ at $95 \% \mathrm{CI}$ of 1.74 to 14.29 and $\mathrm{NNT}(\mathrm{Ham})=10$ at $95 \% \mathrm{CI}$ of $22.3 \mathrm{o}$ (Ham) to 6.18 (Ham), while total number of women lost to follow up were not significantly different between two groups. Moreover, table (4), shows that the total number of women completed the trial were not significantly different between both groups and in total no more than $20 \%$ of women lost to follow up. As regards the cost, table( 4 )shows that the cost of $100 \mathrm{mg}$ element iron was $0.42 \mathrm{LE}$. For SRFS and 0.71 LE.for IPC while the cost of 4 weeks is $12 \mathrm{LE}$ for SRFS and 19.8 LE for IPC, while the average direct and indirect cost of drugs were significantly less in IPC at $\mathrm{T}_{1}, \mathrm{~T}_{2}, \mathrm{~T}_{3}$ as $\mathrm{P}<0.0001, \mathrm{P}<0.0001, \mathrm{P}$ $<0.0001$ respectively. The averaged used $100 \mathrm{mg}$ elemental iron capsules were significantly more in IPC arm $\mathrm{P}=0.003$.

As regards the pregnancy outcomes, women included in this trial and followed up to 12 week did not exclude due to development of pregnancy induced medical disorders. Women whom couldn't tolerate oral iron treated with intravenous iron. No women developed severe fetal complications, and no adverse fetal outcomes could be attributed to the used medicinal iron were noticed, while 4 women in SRFS and 5 in IPC developed preterm labor and 4 neonates in either arm were also incubated 4 women in SRFS, and 6 women in IPC had primary postpartum hemorrhage; however, no transfusion was needed.

Figure (I): CONSORT flow diagram of GIDA trial recruitment and follow up (at $\mathrm{T}_{1}, \mathrm{~T}_{2}, \mathrm{~T}_{3}$ ) evaluation between SRFS and IPC groups.

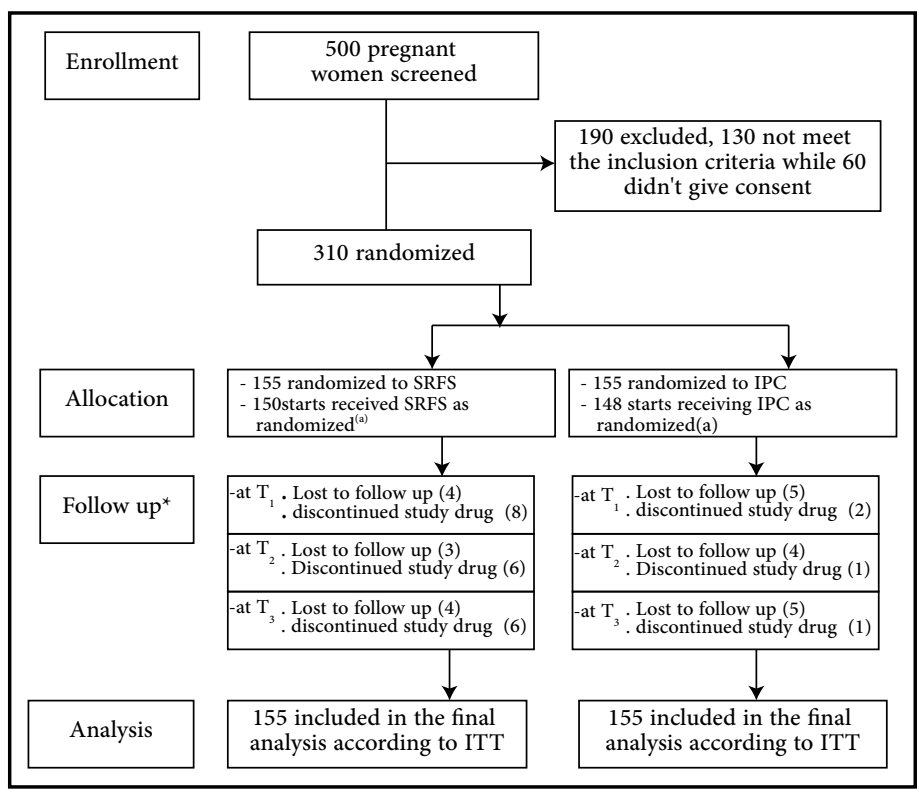

\section{Abbreviation: CONSORT:}

Consolidated standards of reporting trials, GIDT: Gestational iron deficiency anemia, $\mathbf{T}_{\mathbf{1}}$ : Follow up after 4 weeks, $\mathbf{T}_{\mathbf{2}}$ : Follow up after 8 weeks, $\mathbf{T}_{\mathbf{3}}$ : Follow up after 12 weeks, SRFS: Sustained released ferrous sulphate , IPC: Iron polymaltose complex, ITT: Intention to treatment analysis policy. (a)Fivewomenare theSRFSgroupand sevenwomen in IPC withdrawn their consent after randomization. (b) Lost to follow up at T1, T2, T3 despite attempts to contact them by any available way of contact while those decided to stop study medication were due to severe gastrointestinal intolerability. 
Table (1): Baseline demographic, clinical and laboratory criteria of participants allocated to SRFS or IPC in GIDA trial.

\begin{tabular}{|c|c|c|c|c|}
\hline Variable & $\begin{array}{c}\text { SRFS group } \\
(\mathrm{no}=155)\end{array}$ & $\begin{array}{l}\text { IPC group } \\
(\mathrm{no}=155)\end{array}$ & $\Delta(95 \%$ CI $)$ & P value \\
\hline - Age (y)* & $29.6 \pm 3.6(8-42)$ & $30.2 \pm 4.6(19-38)$ & $-0.6(0.32,-1.52)$ & $=0.20$ \\
\hline - BMI (kg/m2)* & $30.5 \pm 6.1(20.2-35.6)$ & $29.8 \pm 5.6(21.2-34.6)$ & $0.7(-2.00,6.60)$ & $=0.29$ \\
\hline - Gravidity (n)* & $4.2 \pm 1.6(1-10)$ & $3.9 \pm 1.8(1-9)$ & $0.3(0.68,-0.08)$ & $=0.12$ \\
\hline - Parity (n)* & $3.1 \pm 1.3(0-8)$ & $2.9 \pm 1.6(0-7)$ & $0.2(0.52,-0.12)$ & $=0.22$ \\
\hline -Urban area residents(n)** & $83(53.5 \%)$ & $73(47 \%)$ & $6.5 \%(4.58,-17.36)$ & $=0.25$ \\
\hline -Rural area residents $(\mathbf{n}) * *$ & $72(46.5 \%)$ & $82(53 \%)$ & $-6.5 \%(-4.58,17.36)$ & $=0.25$ \\
\hline \multicolumn{5}{|l|}{ - Prior cesarean section** } \\
\hline - none & $122(78.7 \%)$ & $120(77.4 \%)$ & $1.3 \%(7.91,-10.49)$ & $=0.78$ \\
\hline$-\geq 1$ & $33(21.3 \%)$ & $35(22.6 \%)$ & $-2 \%(-8.47,12.41)$ & $=0.71$ \\
\hline - Gestational age (wks)* & $23.6 \pm 5.2(14-32)$ & $24.2 \pm 4.8(14-32)$ & $-0.6(-0.51,1.71)$ & $=0.29$ \\
\hline \multicolumn{5}{|l|}{-Hematologic parameters* } \\
\hline$-\mathrm{HB}(\mathrm{gm} / \mathrm{dl})$ & $8.38 \pm 0.69(8-9.8)$ & $8.41 \pm 0.71(8-9.9)$ & $-0.03(0.12,-0.18)$ & $=0.70$ \\
\hline - PCV $(\%)$ & $24.2 \pm 5.62(22-28)$ & $24.9 \pm 6.72(22-29)$ & $-0.7(0.68,-2.08)$ & $=0.32$ \\
\hline - MCV (FL) & $70.81 \pm 6.8(65-78)$ & $70.61 \pm 7.8(66-79)$ & $0.2(-1.83,1.43)$ & $=0.81$ \\
\hline$-\mathrm{MCH}(\mathrm{pg})$ & $22.82 \pm 4.37(18-24)$ & $21.78 \pm 5.28(17-33)$ & $1.04(-2.12,0.04)$ & $=0.05$ \\
\hline - MCHCC (g/l) & $289.7 \pm 64.65(270-310)$ & $291.8 \pm 68.67(268-308)$ & $-2.1(12.80,-17.00)$ & $=0.78$ \\
\hline$-\mathrm{RDW} \%$ & $14.82 \pm 1.68(12-16)$ & $14.68 \pm 1.72(12-16)$ & $0.14(-0.52,0.24)$ & $=0.46$ \\
\hline -Serum ferritin (ng/ml)* & $10.61 \pm 8.52(2-14)$ & $11.12 \pm 9.18(3-13)$ & $-0.51(1.46,-2.48)$ & $=0.61$ \\
\hline
\end{tabular}

Abbreviation: SRFS: Sustained released ferrous sulphate (ferroful)R, IPC: Iron polymaltose complex (Haemojet $\AA)$, GIDA: Gestational iron deficiency anemia, $\Delta$ (95\% CI): Point estimate difference (95\% confidence interval), BMI: Body mass index,HB: hemoglobin, PCV: Packed cell volume, MCV: Mean corpuscular volume, Pg: Pico gram, MCH: Mean corpuscular hemoglobin, MCHC: Mean corpuscular hemoglobin concentration, FL:Femto litter, Wks.: Weeks, Kg: Kilogram, $\mathbf{m}^{2}$ : Squared meter. - Values were given as mean \pm standard deviation (range)* or number (percentage)** - $\mathbf{P}<\mathbf{0 . 0 5}$ : Statistically significant.

Table (2): Therapeutic outcomes differences between participants received SRFS and IPC in GIDA trial.

\begin{tabular}{|c|c|c|c|c|}
\hline Variable* & $\begin{array}{c}\text { SRFS group } \\
(\text { no }=155)\end{array}$ & $\begin{array}{l}\text { IPC group } \\
(\text { no }=155)\end{array}$ & $\Delta(95 \% \mathrm{CI})$ & P value \\
\hline \multicolumn{5}{|l|}{ - HB (gm/dl) } \\
\hline$-\mathrm{T}_{1}: \mathrm{HB}(\mathrm{gm} / \mathrm{dl})$ & $8.93 \pm 0.59(8-10.6)$ & $9.11 \pm 0.12(8-10.8)$ & $-0.18(-0.08,-0.27)$ & $=0.0002$ \\
\hline$-\mathrm{T}_{2}: \mathrm{HB}(\mathrm{gm} / \mathrm{dl})$ & $9.86 \pm 0.67(8-10.8)$ & $10.09 \pm 0.26(8-11.2)$ & $-0.23(-0.11,-0.34)$ & $=0.0001$ \\
\hline$-\mathrm{T}_{3}: \mathrm{HB}(\mathrm{gm} / \mathrm{dl})$ & $10.76 \pm 0.87(8-11.5)$ & $10.98 \pm 0.23(8-11.6)$ & $-0.22(-0.07,-0.36)$ & $=0.0025$ \\
\hline \multicolumn{5}{|l|}{$\begin{array}{l}\text {-Changes in (HB gm/dl) } \\
\text { from baseline }\end{array}$} \\
\hline$-\Delta_{1}\left(\mathrm{~T}_{1}-\mathrm{T}_{0}\right) \mathrm{HB}(\mathrm{gm} / \mathrm{dl})$ & $0.55 \pm 0.33(0-1.6)$ & $0.70 \pm 0.34(0-1.8)$ & $-0.15(-0.07,-0.22)$ & $=0.0001$ \\
\hline$-\Delta_{2}\left(\mathrm{~T}_{2}-\mathrm{T}_{0}\right) \mathrm{HB}(\mathrm{gm} / \mathrm{dl})$ & $1.48 \pm 0.84(6-2.5)$ & $1.68 \pm 0.33(0-2.8)$ & $-0.2(-0.05,-0.34)$ & $=0.0064$ \\
\hline$-\Delta_{3}\left(\mathrm{~T}_{3}-\mathrm{T}_{0}\right) \mathrm{HB}(\mathrm{gm} / \mathrm{dl})$ & $2.38 \pm 0.89(0-3.3)$ & $2.57 \pm 0.32(0-3.4)$ & $-0.19(-0.04,-0.33)$ & $=0.012$ \\
\hline $\begin{array}{l}\text {-Serum ferritin }(\mathrm{ng} / \mathrm{ml}) \text { at } \\
\text { 12wks }\end{array}$ & $68.52 \pm 36.56(50-120)$ & $79.25 \pm 16.95(60-130)$ & $-10.73(-4.36,-17.09)$ & $=0.001$ \\
\hline $\begin{array}{l}\text {-Changes in serum ferritin } \\
\text { from Baseline }\left(T_{3}-T_{0}\right)\end{array}$ & $58.11 \pm 32.34(36-110)$ & $69.63 \pm 13.61(46-120)$ & $-11.52(-5.97,-17.06)$ & $=0.0001$ \\
\hline
\end{tabular}


Abbreviation:SRFS: Sustained released ferrous sulphate (ferroful) ${ }^{\mathrm{R}}$, IPC: Iron polymaltose complex (Haemojet ${ }^{\circledR}$ ), GIDA: Gestational iron deficiency anemia, HB: Hemoglobin, $\mathbf{T}_{\mathbf{1}}, \mathbf{T}_{\mathbf{2}}, \mathbf{T}_{\mathbf{3}}$ : Follow up after 4 weeks, 8 weeks, 12 weeks respectively. $\Delta_{1}, \Delta_{2}, \Delta_{3}$ : Differences between baseline values and values at $\left(\mathrm{T}_{0}\right)$ and $\mathrm{T}_{1}, \mathrm{~T}_{2}, \mathrm{~T}_{3}$ respectively, $\Delta \mathbf{( 9 5 \%} \mathbf{C I})$ : Point estimate difference ( $95 \%$ confidence interval).

-Values were given as mean \pm standard deviation (range)*

- P < 0.05: Statistically significant.

Table (3): Adverse side events (ASE) outcomes difference between women received SRFS and IPL in GIDA trial.

\begin{tabular}{|l|c|c|c|c|}
\hline \multicolumn{1}{|c|}{ Variable** } & $\begin{array}{c}\text { SRFS group } \\
(\mathbf{n o = 1 5 5 )}\end{array}$ & $\begin{array}{c}\text { IPC group } \\
(\mathbf{n o}=\mathbf{1 5 5})\end{array}$ & $\Delta(\mathbf{9 5 \%}$ CI) & P value \\
\hline -Nausea & $56(36.1 \%)$ & $28(18.1 \%)$ & $18 \%(8.13,27.42)$ & $=0.0004$ \\
\hline - Vomiting. & $48(30.9 \%)$ & $16(10.3 \%)$ & $20.6 \%(11.71,29.18)$ & $<0.0001$ \\
\hline - Constipation. & $36(23.3 \%)$ & $10(6.5 \%)$ & $16.7 \%(8.91,24.51)$ & $<0.0001$ \\
\hline - Diarrhea. & $30(19.4 \%)$ & $6(3.8 \%)$ & $15.6 \%(8.65,22.83)$ & $<0.0001$ \\
\hline - Metallic toste & $25(16.1 \%)$ & $4(2.6 \%)$ & $13.5 \%(7.21,20.28)$ & $<0.0001$ \\
\hline - Headache & $30(19.4 \%)$ & $11(7.1 \%)$ & $12.5 \%(4.78,19.89)$ & $=0.0001$ \\
\hline - Epigastric discomfort. & $85(54.8 \%)$ & $43(27.7 \%)$ & $27.1 \%(10.22,37.08)$ & $<0.0001$ \\
\hline - Abdominal caliky pain & $95(61.3 \%)$ & $54(34.8 \%)$ & $26.5 \%(15.44,36.65)$ & $<0.0001$ \\
\hline - Pruritis. & $8(5.2 \%)$ & $1(0.6 \%)$ & $4.6 \%(0.75,9.32)$ & $=0.016$ \\
\hline - Dyspnea & $20(12.9 \%)$ & $3(1.9 \%)$ & $11 \%(5.33,17.31)$ & $=0.0002$ \\
\hline - Women with $\geq 2$ ASE & $54(34.8 \%)$ & $21(13.5 \%)$ & $21.3 \%(11.86,30.29)$ & $<0.0001$ \\
\hline - Women without any ASE & $32(20.6 \%)$ & $65(41.9 \%)$ & $21.3 \%(11.02,-30.97)$ & $=0.0001$ \\
\hline - Women with severe ASE & $20(12.9 \%)$ & $4(2.6 \%)$ & $10.3 \%(4.44,16.68)$ & $=0.0007$ \\
\hline
\end{tabular}

Abbreviation: ASE: Adverse side events, SRFS: Sustained released ferrous sulfate(ferroful) ${ }^{\mathrm{R}}$, IPC: Iron polymaltose complex (Haemojet $\left.{ }^{\circledR}\right)$, GIDA: Gestational iron deficiency anemia, $\Delta$ (95\% CI): Point estimate difference ( $95 \%$ confidence interval).

- Values were given as numbers and percentages**

- P < 0.05: Statistically significant.

Table (4): Compliance, costand others outcomes differences between women received SRFS and IPC in GIDA trial.

\begin{tabular}{|c|c|c|c|c|}
\hline Variable & $\begin{array}{c}\text { SRFS group } \\
(\mathbf{n o = 1 5 5 )}\end{array}$ & $\begin{array}{c}\text { IPC group } \\
(\mathbf{n o}=\mathbf{1 5 5})\end{array}$ & $\Delta(\mathbf{9 5 \%} \mathbf{C I})$ & P value \\
\hline $\mathbf{- ~ C o m p l a i n c e ~}^{(\mathbf{a})}$ at $* *$ & & & & \\
\hline $\mathbf{T}_{\mathbf{1}}:$ & & & & \\
\hline $\mathbf{A}$ & $46(29.7 \%)$ & $60(44.6 \%)$ & $-14.6 \%(-4.14,-25.18)$ & $=0.006$ \\
\hline $\mathbf{B}$ & $40(25.8 \%)$ & $51(32.9 \%)$ & $-7.1 \%(-3.03,17,03)$ & $=0.171$ \\
\hline $\mathbf{C}$ & $34(21.9 \%)$ & $20(12.9 \%)$ & $9 \%(0.52,17.38)$ & $=0.036$ \\
\hline $\mathbf{D}$ & $35(22.6 \%)$ & $15(9.6 \%)$ & $13 \%(4.84,21.09)$ & $=0.0019$ \\
\hline $\mathbf{T}_{\mathbf{2}}:$ & & & & \\
\hline $\mathbf{A}$ & $56(36.2 \%)$ & $74(47.7 \%)$ & $-11.5 \%(-0.52,-22.04)$ & $=0.040$ \\
\hline $\mathbf{B}$ & $36(23.2 \%)$ & $53(34.2 \%)$ & $-11 \%(-0.92,-20.78)$ & $=0.032$ \\
\hline $\mathbf{C}$ & $27(17.4 \%)$ & $8(5.2 \%)$ & $9.2 \%(2.57,16.07)$ & $=0.006$ \\
\hline $\mathbf{D}$ & $36(23.2 \%)$ & $20(12.9 \%)$ & $10.3 \%(1.71,18.77)$ & $=0.018$ \\
\hline
\end{tabular}




\begin{tabular}{|c|c|c|c|c|}
\hline$T_{3}:$ & & & & \\
\hline $\mathbf{A}$ & $48(30.9 \%)$ & $71(45.8 \%)$ & $-14.9 \%(-4.07,-25.24)$ & $=0.007$ \\
\hline B & $35(22.5 \%)$ & $52(33.5 \%)$ & $-11 \%(-0.99,-20.71)$ & $=0.031$ \\
\hline $\mathbf{C}$ & $30(19.5 \%)$ & $6(3.9 \%)$ & $15.6 \%(8.62,22.85)$ & $<0.0001$ \\
\hline D & $42(27.1 \%)$ & $26(16.8 \%)$ & $10.3 \%(1.06,19.34)$ & $=0.028$ \\
\hline $\begin{array}{l}\text {-The received } 100 \mathrm{mg} \\
\text { elemental iron } \\
\text { capsules }^{(b) *}\end{array}$ & $58.62 \pm 29.63(0-84)$ & $69.61 \pm 22.62(0-84)$ & $-10.99(-5.09,-16.88)$ & $=0.003$ \\
\hline $\begin{array}{l}\text { - Total women } \\
\text { completed the trial** }\end{array}$ & $119(76.7 \%)$ & $130(83.8 \%)$ & $-7.1 \%(1.76,-15.89)$ & $=0.11$ \\
\hline $\begin{array}{l}\text { - Total women lost to } \\
\text { follow up** }\end{array}$ & $11(7 \%)$ & $14(9 \%)$ & $-2 \%(-4.25,8.33)$ & $=0.51$ \\
\hline $\begin{array}{l}\text {-Total women stopped } \\
\text { treatment** }\end{array}$ & $20(12.9 \%)$ & $4(2.5 \%)$ & $10.4 \%(4.56,16.77)$ & $=0.0006$ \\
\hline $\begin{array}{l}\text { - Cost of } 100 \mathrm{mg} \text { EI } \\
(\mathrm{LE})(\mathrm{C}\end{array}$ & 0.42 & 0.71 & NA & NA \\
\hline $\begin{array}{l}\text { - Cost of } 4 \text { wk iron } \\
\text { (LE)@ }\end{array}$ & 12 & 19.8 & NA & NA \\
\hline $\begin{array}{l}\text { - Drug cost in } 4 \text { wks. } \\
(\mathrm{LE})^{*}\end{array}$ & $30.61 \pm 6.82(12-80)$ & $23.81 \pm 3.21(19.8-60)$ & $6.8(7.99,5.60)$ & $<0.0001$ \\
\hline $\begin{array}{l}\text { - Drug cost in 8wks. } \\
\text { (LE)* }\end{array}$ & $59.86 \pm 11.21(24-150)$ & $51.61 \pm 8.31(39.6-160)$ & $8.2(10.45,6.04)$ & $<0.0001$ \\
\hline $\begin{array}{l}\text { - Drug cost in } 12 \text { wks. } \\
\text { (LE)* }\end{array}$ & $87.41 \pm 16.31(36-200)$ & $68.71 \pm 12.31(59.4-210)$ & $18.7(21.92,15.47)$ & $<0.0001$ \\
\hline
\end{tabular}

Abbreviation: SRFS: Sustained released ferrous sulphate $\left(\right.$ ferroful) ${ }^{\mathrm{R}}$, IPC: Iron polymaltose complex (Haemojet $\left.{ }^{\circledR}\right)$, GIDA: Gestational iron deficiency anemia, EI: Elemental iron, L.E: Egyptian pound, $\mathbf{T}_{1}, \mathbf{T}_{2}$, $\mathbf{T}_{3}$ : Follow up period at 4 weeks, 8 weeks, 12 weeks respectively. $\Delta$ (95\% CI): Point estimate difference $(95 \%$ confidence interval), NA : Inonapplicable

- Values were given as mean \pm standard deviation (range)* or number (percentage)**.

- P $<$ 0.05: Statistically significant.

a) Compliance was graded as $\mathbf{A}$ (best compliance) if women utilized $\geq 75 \%$ of calculated iron capsules per 4 weeks of follow up which be 21 Haemjet capsules in IPC group and 45 ferroful capsules in SRFS group. $\mathbf{B}($ good compliance) if women utilized $\geq 50 \%$ but $<75 \%$, C: (fair compliance) if utilized $\geq 25 \%$ but $<50 \%$ and $\mathbf{D}$ (poor compliance) if women utilized $<25 \%$ in group $\mathrm{d}$ included also, women withdrawn their consent after randomized as well as women stopped to used treatment at any follow up periods and those lost to follow.

b): The used capsules according to its elemental iron (EI), in SRFS the four weeks period using of 60 capsules $\simeq 100 \mathrm{mg} \mathrm{EI} /$ daily while in IPC the four week period of 28 capsules $=100 \mathrm{mg}$ EI/daily.

c): The actual cost at the trial time in Egyptian pound.

\section{Discussion}

Iron deficiency anemia is the most common type of anemia during pregnancy ${ }^{(1,2)}$. National and international guidelines recommended screening and treating ID and IDA. Oral iron is the first line recommended by this agencies to correct ID and $\operatorname{IDA}^{(5,6,7,8)}$. While pregnant women compliance with oral iron is a significant problem due to gastrointestinal intolerability ${ }^{(7,9,10)}$ as well as systemic side effects ${ }^{(20)}$ due to an increase of non-transferrin bounding iron $(\mathrm{NTBI})^{(21,22)}$ following passive intercellular diffusion of intestinal medicinal iron ${ }^{(21,22,23,24)}$. Oral ferrous $\left(\mathrm{Fe}^{+2}\right)$ salts, even sustained release formulations associated with high intestinal $\mathrm{Fe}^{+2}$ with subsequent gastrointestinal sequels $^{(12,24)}$ as well as excessive para-cellular passive diffusion resulting in high serum $\mathrm{NTBI}^{(22,25,26)}$ which irregularly uptake by endocrinal and cardiac muscle calls ${ }^{(12,21,22,25,26)}$ with consequent chronic 
exposures of vital cells to high oxidative stress of weakly bound $\left(\mathrm{Fe}^{+3}\right)$ (NTBI) which promote lipid peroxidation, membrane disruption, enzyme inactivation, sulfhydryl oxidation and breakage strand of DNA which ultimately resulted in organ malfunction $^{(8,27,28)}$,as well as consequently followed with systemic side effects such as hypotension, nausea, lower back pain, abdominal colicky pain, metallic taste and peripheral edema ${ }^{(12,20)}$. However IPC is non ionic ferric $\left(\mathrm{Fe}^{+3}\right)$ iron corein complex $^{(12,26,29)}$ polymaltose shall rendered the IPC molecule soluble in water at wide $\mathrm{PH}$ range as well as instable state of enterocyte absorption while the passive extracellular diffusion even if occurred is minimal and the passed IPC molecules to serum rapidly uptake by reticuloendothelial cells as that occurred with intravenous IPC and resulted NTBI is very low. NTBI after $100 \mathrm{mg}$ elemental iron of ferrous salts compared to $100 \mathrm{mg}$ elementaliron of IPC elemental iron is nine $\mu \mathrm{M}$ to $0.7 \mu \mathrm{M}$, so both systemic, as well as local gastrointestinal ASE, are high with ferrous salts compared to IPC ${ }^{(22,25,26)}$.

This open-label, prospective, Controlled, randomized, concealed allocation, superiority trial showed that IPC oral formulation is significantly tolerable as well as effective than SRFS oral formulation in treating GIDA in second and early third trimester as the average increase in HB and SF were more in IPC group at all follow up time periods. However, if pre-treatment HB and SF compared to any post-treatment laboratory changes a significant difference was noticed in either study group. Also, this study showed that significantly more women in IPC arm were adherent to the prescribed oral iron formulations while significantly more women stopped oral iron in the SRFS arm.

Oral iron supplementations for GIDA were extensively studied including ferrous salts, iron chelated amino-acids $^{(33,34)}$, lactoferrins ${ }^{(35,36)}$ even in developing countries as Egypt, despite profoundly high prices of following formulations. Cheap, high elemental iron, IPC formulation was introduced to Egyptian market few years age namely, Haemojet $₫$ capsule, this takes our attention to conducting this trial. Also after careful search in databases as CENTRAL, MEDLINE, EMBASE, few trials address efficacy, tolerability, compliance of IPC versus ferrous salts in GIDA mostly conducted at In$\mathrm{dia}^{(15,30,32)}$, South America ${ }^{(16)}$ and trial concentrated on oxidative stress between $\left(\mathrm{Fe}^{+3}\right)$ IPC and ferrous $\left(\mathrm{Fe}^{+2}\right)$ salts in anemic and non anemic pregnant women from Egypt ${ }^{(17)}$ and one study from Isra$\mathrm{el}^{(19)}$ and the most recent from Indonesia ${ }^{(18)}$.Indian trial of Saha et al. ${ }^{(15)}$ more or less like our trial and shows similar results despite their trial didn't show a significantly higher increase in $\mathrm{HB}$, and this could be due to smaller sample size in their trial,52 patients in ferrous FS versus 48 patients in IPC groups as well as shorter follow up period as their trial continued only for 8 weeks but our study extended to 12 weeks. Saha et al. ${ }^{(15)}$ results regards oral iron formulations tolerability were in agreement with our results as well as rates of ASE and cost related to management of such ASE, however total costs reported by Saha et al. were insignificant higher with IPG as we found it significantly lower in group of IPC but this lost is in local Egyptian currency, and this May be subjected to change. Despite that, other Indian trials ${ }^{(30,31,32)}$ shows contradictory results, however, their designs were different from our trial. The south America trial of Ortiz et al. is more or less similar in design to our study, and their results were in agreement of our results regards significantly better tolerability and more compliance with IPC than FS oral formulation, however, regards efficacy they reported significant higher change in serum ferritin at 90 days to follow up like us but they didn't show significant increase in HB from baseline to any follow up period at 30,60 days despite higher changes in HB in IPC group and this could be attributable to their lower sample size (41 in IPCvs. 39 in FS). The Indonesia trial of Astuti et al. ${ }^{(18)}$ was designed in pre-test - post - test approach and shows significantly active IPC oral formation and didn't include any comparison. The Israel trial of Mebowed et al. ${ }^{(19)}$ included comparison between ferrous fumarate (Mostly used 46.8\%) ferrous sulphate $(31.8 \%)$, ferric polymaltose $(12.4 \%)$ and ferric bisglycinate $(7.3 \%)$, their results regards IPC and SRFS were in line with our results regards discontinuation rate $(22 / 56(39.3 \%)$ versus $39 / 90$ $(43.3 \%)$ despite it doesn't reach significant level and that their study isn't randomized rather than evaluation of real situation of oral iron supplementation via questionnaire. The Egyptian trial of $\boldsymbol{A l y}$ et $\boldsymbol{a l} .^{(17)}$, included 50 pregnant women with IDA, 25 allocated to FS and 25 allocated to IPC, despite that they didn't report the trade name of used oral 
medication and reported only that FS group used $100 \mathrm{mg}$ FS twice daily, and IPC consumed $200 \mathrm{mg}$ IPC once daily, they found both are effective in correction of HB deficiency at 4 and 8 weeks of interval follow up, but they didn't report regards tolerability of both agents.

Strengths in this study were more as being prospective, randomized, its allocation was concealed and knowing the coming assignments isn't possible as we used closed opaque envelopes, adequate powered to detect change in $\mathrm{HB}$, as 310 women with GIDA were included in this trial compared to lower sample sizes of any present trial to date, as well as variation in studied population included different socioeconomic cultures and the trial address important item, as GIDA is a highly prevalent problem specially in Egypt and pregnancy related gastrointestinal disturbance may interfere with compliance on irritant oral medicinal iron formulations. We considered conduction of this trial more or less in realistic fashion utilized available, cheap, easily founded formulations in Egyptian drug market a valuable strength point of this trial.

Limitations of this trial may be included the open - label nature which may impact the subjectively reported oral iron related gastrointestinal and systemic adverse side events. This open-label nature may also, has a negative impact on pregnant women with IDA in compliance with oral formulations. However other efficacy study outcomes are not subjected to this open-label nature as being objective laboratory outcomes.However we found designing study in this fashion resulted in more adherence to study as well as drug consumption, as we used a real market drug, also we found reminding women with next time of follow up more effective in adherence to the study. We recommended for future researches the double-blinded, placebo-controlled OR double - dummy fashion study design comparing SRFS with IPC for treat GIDA concentrated and powered to detect differences in tolerability as well as compliance in addition to efficacy.

\section{Conclusion}

This prospective, open-label, multicenter, randomized, parallel group, concealed allocation, superiority trial demonstrated that oral iron polymaltose complex soft gelatinous capsule containing 100 mg elemental iron was significantly more effective in term of hemoglobin and serum ferritin changes, more tolerable in terms of gastrointestinal adverse side events as well as women were more complaint with its usage as well as the total iron related costs were less than sustained released dried ferrous sulphate in spansule hard capsules as regard managing women with gestational iron deficiency anemia in the second and early third, trimester pregnancy period.

\section{Acknowledgment}

The authors want to thank their colleges, fellows, caregivers, nurses, health workers in Benha University Hospital and in their clinics For helping them in completing this work

\section{Conflict of interests}

We declare that we did not have any conflict of interests to be disclosed as well as we are the only responsere and owner of data presented in this trial as well as founders of this study.

\section{References}

1. de Benoist B, McLean E, Egli I, Cogswell M. Worldwide prevalence of Anaemia 1993 - 2005: WHO global Database on Anemia. Geneva: WHO; 2008. http://whqlibdoc.who.int/publications/2008/9789241596657_eng. pdf?ua $=1$.

2. Xiong X, Buekens P, Alexander S, Demianczuk N, Wollast E. Anemia during, pregnancy and birth outcome: a meta - analysis. Am J Perinatol 2000; 17: $137-46$.

3. Allen LH. Anemia and iron deficiency: effects on pregnancy outcome. Am J ClinNutr 2000; 71 (suppl. 5): $1280 \mathrm{~S}-4 \mathrm{~S}$.

4. Di Renzo GC, Spano F, Giardina I, Brillo E, Clerici $\mathrm{G}$, Roura IC. Iron deficiency anemia in pregnancy. Womens Health (Lond) 2015: $11: 891$ - 900 .

5. WHO. Haemoglobin concentrations for the diagnosis of anaemia and assessment of severity. Vitamin and Mineral Nutrition Information System, Geneva: World Health Organization; 2011 (WHO/ NMH/NHD/MNM/11.1)http://apps.who.int/iris/ bitstream/10665/85839/3.WHO_NMH_NHD_ MN-M.11.1..eg.pdf?ua=1(Accessed $6{ }^{-}$March 2017). 
6. CDC. CDC criteria for anemia in children and childbearing aged women Morb Mortal Wkly Rep 1989; 38 (22) : 400-4.

7. Pavord S, Myers B, Robinson S, Allard S, Strong J, Oppenheimer $\mathrm{C}$, et al. UK guidelines on the management of iron deficiency in pregnancy. $\mathrm{Br} \mathrm{J}$ Haematol 2012; 156: 588 - 600.

8. WHO. Guideline: Daily iron and folic acid supplementation in pregnant women. Geneva: World Health Organization; 2012.

9. Chandra I, Sun L. Iron status and choice of iron therapy during pregnancy: advantages and disadvantages. Int J Reprod Contracept Obstet Gynecol. 2015, Oct; 4(5) : 1264 - 1271.

10. Tandon R, Jain A, Malhotra P. Management of iron deficiency anemia in pregnancy in India. Indian $\mathrm{J}$ Hematol Blood Transfus, 2018.

11. Murray-Kolb L. Maternal mortality, child mortality, perinatal mortality, child cognition, and estimates of the prevalence of anemia due to iron deficiency, CHERG.

12. Geisser P, Burckhardt S. The pharmacokinetics and pharmacodynamics of Iron preprations. Pharmaceutics 2011, 3: 12 - 33 .

13. Palacios S. Ferrous versus ferric oral iron formulations for the treatment of iron deficiency: a clinical overview. The scientific world Journal volume 2012, Article ID 846824, 5. doi:10.1100/2012/846824.

14. Berber I, Diri H, Erkurt MA, Aydogdu I, Kaya E and Kuku I.Evaluation of ferric and ferrous iron therapies in women with iron deficiency anemia. Hindawi publishing corporation advances in hematology. Volume 2014, Article ID 297057, 6 pages, http://dx.doi.org/10.1155/2014/297057.

15. Saha L, Pandhi P, Gopalan S, Malhotra S. Comparison of efficacy, tolerability and cost of an iron polymaltose complex with ferrous sulfate in the treatment of iron deficiency anemia in pregnant women. Med Gen Med. 2007; 9(1) : 1.

16. Ortiz R, Toblli JE, Romero JD, Monterrosa B, Ferer C, Macagno E, Breymann C. Efficacy and safety of oral iron (III) polymaltose complex versus ferrous sulfate in pregnant women with iron deficiency anemia a multicenter, randomized, Controlled study. J Matern Fetal Neonatal Med 2011; 24: $1347-1352$.
17. Aly SS, Fayed HM, Ahmed SS, Abdella AH, Tmam AA, Mohammed NA. Effects of oral iron (ferrous versus ferric) supplementation on oxidative stress and antioxidant status in pregnant women with iron deficiency: the controlled trial. The Egyptian Journal of Haematology, 2016;

18. Astuti CP, Widyawati MN, Pujiastuti SE. The effect of iron polymaltose complex tablet administration to increase hemoglobin level among pregnant women with anemia. ICASH 2017; $246-251$.

19. Melamed N, Ben-Haroush A, Kaplan B, Yogev Y. Iron supplementation in pregnancy - does the preparationmatter?ArchGynecolObstet2007;276:601-4. 19) NirMelamed, Avi Ben - Haroush, Boris Kaplan, YrivYogev. Iron supplementation in pregnancy - does the preparation matter? Arch GynecolObstet (2007), $276: 601-604$.

20. Chandler G, Harchowal J, Macdougall IC. Intravenous iron sucrose: establishing a safe dose. Am. J. Kidney Dis. 2001;38:988-991. [PubMed]

21. Geisser P, Philipp E. True iron bioavailability, iron pharmacokinetics and clinically silent side effects. Nutr. Immun. Health. 2009;1:3-11.

22. Dresow B, Petersen D, Fischer R, Nielsen P. Non-transferrin-bound iron in plasma following administration of oral iron drugs. Biometals. 2008;21:273-276. [PubMed]

23. Evans RW, Rafique R, Zarea A, Rapisarda C, Cammack R, Evans PJ, Porter JB, Hider RC. Nature of non-transferrin-bound iron: studies on iron citrate complexes and the thalassemic sera. J. Biol. Inorg. Chem. 2008;13:57-74. [PubMed]

24. Fuqua BK, Vulpe CD, Anderson GJ. Intestinal iron absorption. Journal of trace elements in medicine and biology 26 (2012): $115-119$.

25. Macdougall IC. Strategies for iron supplementation: oral versus intravenous. Kidney Int. Supp1. 1999;69:S61-S66. [PubMed]

26. Ekenved G, Norrby A, Sölvell L. Serum iron increase as a measure of iron absorption -studies on the correlation with total absorption. Scand. J. Haematol.1976; 17(Suppl. 28):31-49. [PubMed]

27. Crichton RR, Danielson BG, Geisser P. Iron Therapy with Special Emphasis on Intravenous Administration. 4th ed. UNI-MED Verlag AG; Bremen, Germany: 2008. 
28. Geisser P, Müller A. Pharmacokinetics of iron salts and ferric hydroxide-carbohydrate complexes. Drug Res. 1987;37:100-104. [PubMed] 28) Oudit GY, Trivieri MG, Khaper N, Liu PP, Backx PH. Role of L-type Ca2+ channels in iron transport and iron-overload cardiomyopathy. J. Mol. Med. 2006;84:349-364. [PubMed]

29. Jacobs P, Johnson G, Wood L. Oral iron therapy in human subjects, comparative absorption between ferrous salts and iron polymaltose. J. Med. 1984;15:367-377. [PubMed]

30. Rajadhyaksha GC, Shahani S, Pawar D. Evaluation of efficacy and tolerability of iron polymaltose complex tablets in iron deficiency anaemia during pregnancy. JAMA India - the Physician's Update. $2000 ; 3: 53-55$.

31. Reddy PSN, Adsul BB, Gandewr K, Korde KM, Desai A. Evaluation of efficacy and safety of iron polymaltose complex and folic acid (Mumfer) vs. iron formulation (ferrous fumarate) in female patients with anemia. J Indian Med Assoc. 2001; 99 : 154 - 155. [PubMed: 11478761].
32. Mehta BC. Iron hydroxide polymaltose complex cause of persistent anemia at delivery. Indian J Med Sci. 2001; 55-616-620. [PubMed: 12508635].

33. Youssef AM, Shata AF, Kamal HM, El-Saied Y, Ali OF. A comparative study of efficacy, tolerability, and compliance of oral iron preparations for iron deficiency anemia in pregnant women. American Journal of Medicine and Medical Sciences 2014, 4(6): $244-249$.

34. Abdelazim IA, Abu-Faza M, Elbiaa AAM, Othman HS, Alsharif DA, Elsawah WF. Heme iron polypeptide (proferrin ${ }^{\circledR}$-ES) versus iron saccharate complex (Ferrosac) for treatment of iron deficiency anemia during pregnancy. Acta Medica International 2017, Volume 4(1): 56 - 61 .

35. Hemeda HM, Mohamed AA, Islam BA, A Eweis AH. Effectiveness of Bovine lactoferrin versus ferrous fumarate in the management of iron deficiency anemia in pregnancy : randomized clinical trial. Int J Reprod Med Gynecol. 2018; 4(1) : $006=011$.

36. Hashim H, Foda O, Ghayaty E. Lactoferrin or ferrous salts for iron deficiency anemia in pregnancy: A meta-analysis of randomized trials. Eur J Obstet Gynecol Reprod Biol.; 2017, 219: 45 - 52. 